\title{
Laboratory cross-contamination of Mycobacterium tuberculosis: a systematic review and meta-analysis
}

DOI:

10.1007/s00408-019-00241-4

\section{Document Version}

Accepted author manuscript

Link to publication record in Manchester Research Explorer

\section{Citation for published version (APA):}

Barac, A., Karimzadeh-Esfahani, H., Pourostadi, M., Taghi Rahimi, M., Ahmadpour, E., Rashedi, J., Mahdavipoor, B., Samadi Kafil, H., Spotin, A., Hassen Abate, K., Mathioudakis, A., \& Asgharzadeh, M. (2019). Laboratory crosscontamination of Mycobacterium tuberculosis: a systematic review and meta-analysis. Lung. https://doi.org/10.1007/s00408-019-00241-4

\section{Published in:}

Lung

\section{Citing this paper}

Please note that where the full-text provided on Manchester Research Explorer is the Author Accepted Manuscript or Proof version this may differ from the final Published version. If citing, it is advised that you check and use the publisher's definitive version.

\section{General rights}

Copyright and moral rights for the publications made accessible in the Research Explorer are retained by the authors and/or other copyright owners and it is a condition of accessing publications that users recognise and abide by the legal requirements associated with these rights.

\section{Takedown policy}

If you believe that this document breaches copyright please refer to the University of Manchester's Takedown Procedures [http://man.ac.uk/04Y6Bo] or contact uml.scholarlycommunications@manchester.ac.uk providing relevant details, so we can investigate your claim.

\section{OPEN ACCESS}




\section{Lung}

\section{Laboratory cross-contamination of Mycobacterium tuberculosis: a systematic review and meta-analysis \\ --Manuscript Draft--}

Manuscript Number:

Full Title:

Article Type:

Keywords:

\section{Corresponding Author:}

Corresponding Author Secondary Information:

Corresponding Author's Institution:

\section{Corresponding Author's Secondary} Institution:

First Author:

First Author Secondary Information:

Order of Authors:

Order of Authors Secondary Information:

Funding Information:

Abstract:
LUNG-D-19-00061R2

Laboratory cross-contamination of Mycobacterium tuberculosis: a systematic review and meta-analysis

Original Research

Mycobacterium tuberculosis; laboratory diagnosis; cross-contamination; false positive; systematic review; genotyping

Alexander G. Mathioudakis, MD, MRCP(UK)

Wythenshawe Hospital, University of Manchester

Manchester, UNITED KINGDOM

Wythenshawe Hospital, University of Manchester

Aleksandra Barac

Aleksandra Barac

Hannah Karimzadeh-Esfahani

Mahya Pourostadi

Mohammad Taghi Rahimi

Ehsan Ahmadpour

Jalil Rashedi

Behroz Mahdavipoor

Hossein Samadi Kafil

Adel Spotin

Kalkidan Hassen Abate

Alexander G. Mathioudakis, MD, MRCP(UK)

Mohammad Asgharzadeh

\begin{tabular}{|l|l|}
\hline $\begin{array}{l}\text { University of Tabriz (IR) } \\
(37876)\end{array}$ & Dr Ehsan Ahmadpour \\
\hline $\begin{array}{l}\text { Iranian National Sciences Foundation } \\
(843599)\end{array}$ & Dr Ehsan Ahmadpour \\
$\begin{array}{l}\text { National Institute for Health Research } \\
\text { (NIHR Manchester BRC) }\end{array}$ & Dr. Alexander G. Mathioudakis \\
$\begin{array}{l}\text { Ministry of Education, Science and } \\
\text { Technology of the Republic of Serbia } \\
\text { (III45005) }\end{array}$ & Dr Aleksandra Barac \\
\hline
\end{tabular}

Background: Microbiological cultures are the mainstay of the diagnosis of tuberculosis (TB). False positive TB results lead to significant unnecessary therapeutic and economic burden and are frequently caused by laboratory cross-contamination. The aim of this meta-analysis was to quantify the prevalence of laboratory crosscontamination. 
Methods: Through a systematic review of five electronic databases, we identified studies reporting rates of laboratory cross-contamination, confirmed by molecular techniques in TB cultures. We evaluated the quality of the identified studies using the National Institute of Health $(\mathrm{NIH})$ Quality Assessment Tool for Observational Cohort and Cross-Sectional Studies, and conducted a meta-analysis using standard methodology recommended by the Cochrane Collaboration.

Results: Based on 31 eligible studies evaluating 29,839 TB cultures, we found that $2 \%$ ( $95 \%$ confidence intervals [Cl]: $1-2 \%$ ) of all positive TB cultures represent false positive results secondary to laboratory cross-contamination. More importantly, we evaluated the rate of laboratory cross-contamination in cases where a single positive TB culture was available in addition to at least one negative TB culture, and we found a rate of $15 \%(95 \% \mathrm{Cl}: 6-33 \%)$. Moreover, $9.2 \%(91 / 990)$ of all patients with a preliminary diagnosis of TB had false-positive results and received unnecessary and potentially harmful treatments.

Conclusions: Our results highlight a remarkably high prevalence of false positive TB results as a result of laboratory cross-contamination, especially in single-positive TB cultures, leading to the administration of unnecessary, harmful treatments. The need for the adoption of strict technical standards for mycobacterial cultures cannot be overstated. 
3 Aleksandra Barac ${ }^{1,2, \#}$, Hannah Karimzadeh-Esfahani ${ }^{3, \#}$, Mahya Pourostadi ${ }^{4}$, Mohammad Taghi

4 Rahimi $^{5}$, Ehsan Ahmadpour ${ }^{6,7, *}$, Jalil Rashedi ${ }^{8}$, Behroz Mahdavipoor ${ }^{9}$, Hossein Samadi

5 Kafil $^{10,11}$, Adel Spotin ${ }^{11}$, Kalkidan Hassen Abate ${ }^{12}$, Alexander G. Mathioudakis ${ }^{3 *}$, Mohammad

$6 \quad$ Asgharzadeh $^{13}$

7

$8 \quad$ \# These two authors contributed equally to this work.

9

$10{ }^{1}$ Clinic for Infectious and Tropical Diseases, Clinical Centre of Serbia, Belgrade, Serbia.

$11{ }^{2}$ Faculty of Medicine, University of Belgrade, Belgrade, Serbia.

$12{ }^{3}$ Division of Infection, Immunity and Respiratory Medicine, The University of Manchester, 13 Manchester, UK.

$14{ }^{4}$ Biotechnology Research Center, Tabriz University of Medical Sciences, Tabriz, Iran.

$15{ }^{5}$ School of Medicine, Shahroud University of Medical Sciences, Shahroud, Iran

$16{ }^{6}$ Infectious and Tropical Diseases Research Center, Tabriz University of Medical Sciences,

17 Tabriz, Iran

$18{ }^{7}$ Department of Parasitology, Tabriz University of Medical Sciences, Tabriz, Iran

$19{ }^{8}$ Tuberculosis and Lung Disease Research Center, Faculty of Paramedicine, Tabriz

20 University of Medical Sciences, Tabriz, Iran

$21{ }^{9}$ Department of Laboratory Science, Faculty of Paramedicine, Tabriz University of Medical

22 Sciences \& Department of Medical Parasitology, School of Medical Sciences, Tarbiat

23 Modarres University, Tehran, Iran

$24{ }^{10}$ Department of Microbiology, Tabriz University of Medical Sciences, Tabriz, Iran

$25{ }^{11}$ Drug Applied Research Center, Tabriz University of Medical Sciences, Tabriz, Iran 


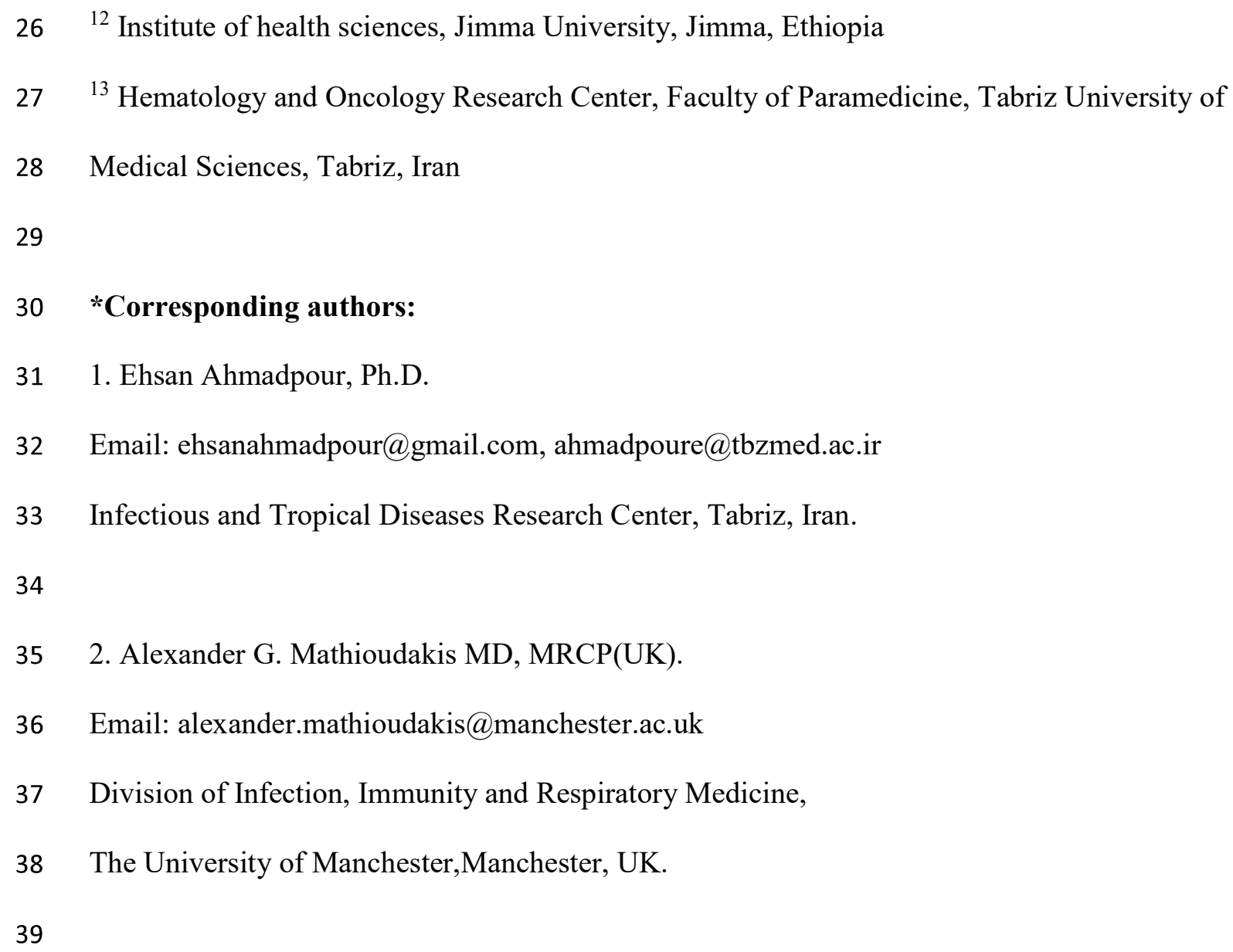




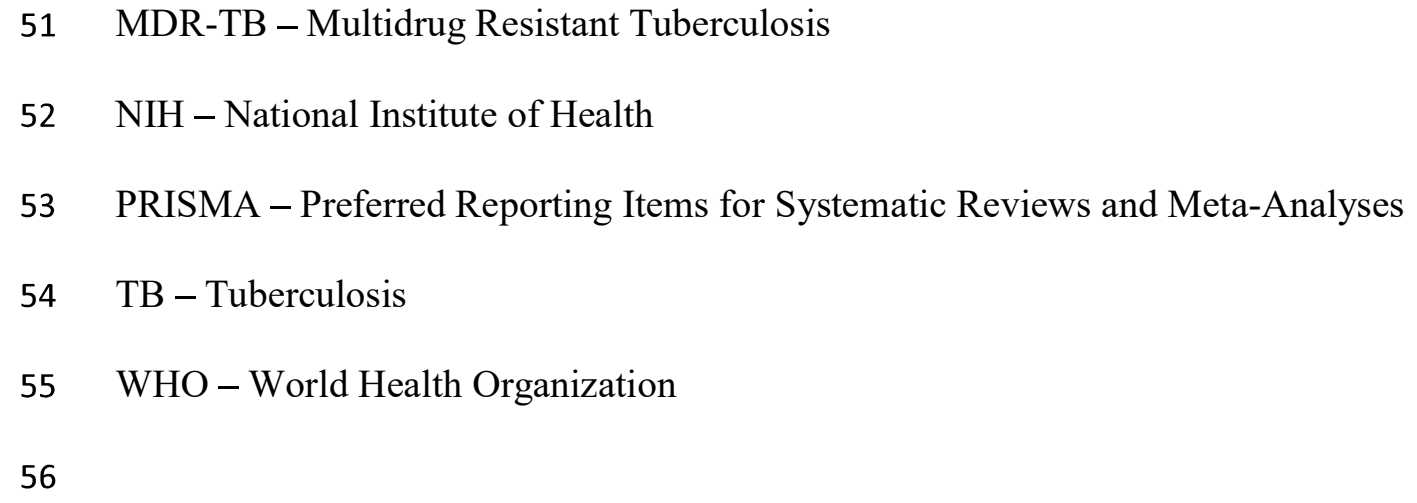

68 Results: Based on 31 eligible studies evaluating 29,839 TB cultures, we found that 2\% (95\% 69 confidence intervals [CI]: 1-2\%) of all positive TB cultures represent false positive results 70 secondary to laboratory cross-contamination. More importantly, we evaluated the rate of 71 laboratory cross-contamination in cases where a single positive TB culture was available in 72 addition to at least one negative TB culture, and we found a rate of $15 \%(95 \% \mathrm{CI}$ : $6-33 \%)$. 73 Moreover, 9.2\% (91/990) of all patients with a preliminary diagnosis of TB had false-positive 74 results and received unnecessary and potentially harmful treatments. 
75 Conclusions: Our results highlight a remarkably high prevalence of false positive TB results 76 as a result of laboratory cross-contamination, especially in single-positive TB cultures, leading 77 to the administration of unnecessary, harmful treatments. The need for the adoption of strict 78 technical standards for mycobacterial cultures cannot be overstated.

\section{Introduction}

82 Despite global efforts to control tuberculosis (TB), the incidence of the condition is growing ${ }^{1}$. 83 According to the World Health Organization (WHO) 2018 report, "TB is one of the top 10 84 causes of death worldwide, and the leading cause from a single infectious agent" ${ }^{2}$. In 2017 , 8510.4 million people were diagnosed with TB and 1.6 million died from the disease (including 860.3 million patients with concomitant HIV infection) $)^{1,2}$. Over $95 \%$ of TB deaths occur in low87 and middle-income countries. Five countries account for $56 \%$ of the total number of cases, with 88 India leading the count, followed by Indonesia, China, the Phillipines, and Pakistan. In 2016, 89 the estimated incidence of TB in children exceeded 1 million. In 2016, an estimated 490000 90 people developed multidrug-resistant TB (MDR-TB) worldwide ${ }^{2}$

91 TB diagnosis is confirmed by the isolation and identification of $\mathrm{M}$. tuberculosis bacillus in 92 microbiological cultures ${ }^{3}$. The accuracy of mycobacterial microbial cultures is limited by the 93 prevalence of false positive and false negative results. Laboratory cross-contamination causing 94 false positive results is not infrequent and has important medical and psychological 95 implications for patients and their families, as well as financial and public health ramifications 96 for the healthcare system ${ }^{4}$. Over the years, different methods have been utilized to limit the 97 burden of laboratory cross-contamination. More than one decade ago, it was recommended to 98 consider a result false positive if there were 5 or less colonies grown on a specific growth 99 media $^{5}$. Since the above method was not reliable, molecular techniques are now used for the 
100 confirmation of $\mathrm{TB}^{6-7}$. IS6110-based restriction fragment length polymorphism typing (RFLP)

101 is a standard method to assess the cross-contamination and transmission of tuberculosis.

102 IS6110-RFLP which is based on the number and genomic site of IS6110 ${ }^{8-9}$. In the cases that

103 the copy number of IS6110 is less than 6 bands, the use of other methods can be helpful ${ }^{13}$.

104 Approaches based on next generation sequencing (NGS) may offer a more accurate 105 assessment $^{14}$.

106 However, the exact burden of false positive mycobacterial cultures resulting from laboratory 107 cross-contamination is unknown. The aim of this systematic review and meta-analysis was to 108 estimate this prevalence in order to facilitate planning accurate, cost-effective diagnostic 109 strategies.

112 Inclusion criteria

113 We included studies reporting on the prevalence of TB-laboratory cross-contamination, 114 detected by genotyping and confirmed by clinico-epidemiological analyses. We did not apply 115 any geographical limitations. We only included studies published during the last 20 years (since 116 1997), as culturing methods and standards have been changing, and we considered that older 117 studies would not reflect current practice. We excluded studies exploring non-TB 118 mycobacteria, those that solely used genotyping to explore cross-contamination without taking 119 into account clinic-epidemiological data, case reports, specific organ TB and those with very 120 limited sample size $(\leq 60)$. We only included studies written in the English language.

\section{Outcome Measures}

123 The outcomes of this meta-analysis include: The proportion of TB laboratory cross124 contamination among (a) all positive TB cultures or smears, (b) single positive TB cultures or 
smears, in cases where the results of at least one additional negative TB culture was available, and (c) all TB cultures or smears (positive or negative). In addition, we assessed the proportion of false-negative results in the same groups.

\section{Search Strategy and Study Selection}

We systematically reviewed the electronic databases of Medline, PubMed, Scopus, ScienceDirect and Cochrane Controlled Register of Trials (CENTRAL), using appropriate controlled vocabulary and free search terms to identify studies evaluating the prevalence of tuberculosis (use TB instead) laboratory cross-contamination, including the following terms: "tuberculosis", "mycobacterium", "mycobacterial”, "cross-contamination", "laboratory diagnosis", "false positive", "culture" and "genotyping". Databases were searched from January 1997 to Jan 2019. Two authors independently screened abstracts and full texts (when appropriate), for eligibility for all identified studies. The study selection process was detailed in a Preferred Reporting Items for Systematic Reviews and Meta-Analyses (PRISMA) flowchart.

\section{Data extraction}

Relevant data including the full reference and study identifiers, study date, study design, eligibility, predefined outcomes, number and characteristics of the participants and details on the outcomes of interest were extracted by two authors independently. Disagreement was resolved through discussion and adjudication by a third investigator.

\section{Quality of the included studies}

We used the National Institutes of Health (NIH) Quality Assessment Tool for Observational Cohort and Cross-Sectional Studies to assess the risk of bias of each included study (available 
150 from: https://www.nhlbi.nih.gov/health-topics/study-quality-assessment-tools). Two authors 151 evaluated risk of bias of the included studies independently. We used funnel plots to assess for 152 publication bias when appropriate.

\section{Analysis}

155 We used $\mathrm{I}^{2}$ statistic to assess statistical heterogeneity within the studies included in each 156 analysis. We conducted prespecified subgroup analyses to explore the causes of heterogeneity 157 in cases with substantial heterogeneity $\left(\mathrm{I}^{2}>50 \%\right)$.

158 We expected significant heterogeneity in our analyses, due to the differences in the standards 159 used in different laboratories and the accuracy of the methodologies used to confirm laboratory 160 cross-contamination in the primary studies. For this reason, we conducted our meta-analyses 161 using the random effects mode. We considered it imperative to present overall estimates, even 162 if the heterogeneity was particularly significant and to declare the limitations. Meta-analyses 163 were performed using $\mathrm{R}$ version 3.4 .4 and the relevant Comprehensive $\mathrm{R}$ Archive Network 164 (CRAN) packages for meta-analysis (meta and metafor).

165 In different prespecified sensitivity analyses for all outcomes (i) we included only studies with 166 low risk of bias and (ii) we divided the studies according to the methodology used to identify 167 TB laboratory cross-contamination. In an additional sensitivity analysis, we also excluded one 168 of the identified studies that found unexpectedly high levels of cross-contamination, which, 169 as reported by the investigators, reflected laboratory specific problems.

\section{Results}

172 Our search results and study selection process are summarized in a PRISMA flowchart (figure 173 1). Briefly, our systematic searches yielded 1,033 records of which we included 32 records 
174

reporting on 31 studies evaluating $\mathrm{n}=29,839$ positive cultures for Mycobacterium tuberculosis ${ }^{3,6,11-39}$. Basic study characteristics are available in table 1.

\section{Study characteristics}

The study population of the included studies ranged between 61 and 8,889 participants. The proportion of positive cultures as a result of laboratory cross-contamination ranged from $0.3 \%$ to $7.84 \%$, with the exception of one $\operatorname{study}^{6}$, which reported significantly larger proportion $(18.2 \%)$, as a result of an extensive episode of cross-contamination involving numerous samples.

Different genotyping methods were used to identify possible laboratory cross-contamination. Most studies $(\mathrm{n}=19)$ used IS6110-RFLP. Others used 12 or 24-loci mycobacterial interspersed repetitive units (MIRU) typing, variable numbers of tandem repeats (VNTR), polymorphic GCrich sequence (PGRS), direct repetitive element (DRE), spoligotyping, and direct repeat (DR)RFLP. In the majority of studies more than one method was performed for genotyping.

\section{Risk of Bias Assessment}

We deemed all of the included studies to be of good $(n=21)$ or fair $(n=10)$ methodological quality (figure 2). Specific limitations included: (i) None of the included studies provided a sample size justification, (ii) The study population was poorly defined in 6 studies, (iii) the participation rate was less than $50 \%$ of the eligible persons in one study and (iv) four studies recruited heterogeneous populations. In addition, our funnel plots suggest the presence of publication bias (figure 3). These may have led to a slight overestimation of the prevalence of laboratory cross-contamination.

\section{Data Synthesis}


198 Overall effect estimates for each outcome are presented in figure 4. The proportion of positive 199 samples secondary to laboratory cross-contamination as a proportion of all positive samples 200 was evaluated by 30 studies, with an overall study population of $n=29,022$. We found a mean 201 proportion of 0.02 with $95 \%$ confidence intervals $(95 \% \mathrm{CI})$ between 0.01 and 0.02 (figure $4 \mathrm{a}$ ). 202 There was significant heterogeneity $\left(\mathrm{I}^{2}=88 \%\right)$ which was resolved by removing the study with 203 unexpectedly high levels of cross-contamination ${ }^{6}$ and separating the studies according to the 204 methods used to identify cross-contamination.

205 We defined single positive a TB culture or smear, in cases where the results of at least one 206 additional TB culture were available and negative. Eight studies reported on cross207 contamination as a proportion of single-positive samples. The mean proportion was $0.15(95 \%$ 208 CI: $0.06-0.33$, figure $4 \mathrm{~b}$ ). The significant heterogeneity was resolved by the exclusion of two 209 studies reporting unexpectedly high proportions of cross-contamination. The mean proportion 210 of the remaining, homogeneous studies was 0.10 ( $95 \% \mathrm{CI}: 0.06,0.15$, figure $4 \mathrm{c})$.

211 Finally, 20 studies provided data on false-positive results and allowed us to assess the number 212 of false-positive results as a proportion of all positive results. The mean proportion was 0.03 213 (95\% CI 0.02, 0.04, figure 4d). The significant heterogeneity was resolved by removing the 214 study with unexpectedly high levels of cross-contamination ${ }^{6}$ and separating the studies 215 according to different methodologies used to identify false positives and cross-contamination. 216 In addition, 9.2\% (91/ 990) of patients with a preliminary diagnosis of TB had false-positive 217 results and consequently received the incorrect treatment ${ }^{3,11-25}$ (16 studies), which leaded to a 218 fatal outcome in eight cases ${ }^{17,23-25}$ (4 studies).

\section{Discussion}

221 In a meta-analysis of 31 studies evaluating 29,839 positive cultures of Mycobacterium 222 tuberculosis, using genotyping and clinico-epidemiological analyses to identify false positive 
223 cultures, we evaluated the global prevalence of false positive Mycobacterial cultures. Our

224 findings point out a remarkably high prevalence of false-positive TB results secondary to 225 laboratory cross-contamination. Specifically, 2\% of all positive TB cultures and, more 226 importantly, one in six (15\%) of all single positive TB cultures, are the results of laboratory 227 cross-contamination. False positive results lead to the unnecessary administration of anti228 tubercular medications, which are associated with side effects and could result in avoidable 229 harm to numerous patients ${ }^{12}$. Indeed, in our meta-analysis we found that up to $9.2 \%$ of patients 230 with a preliminary diagnosis of $\mathrm{TB}$ had a false-positive result and received inappropriate 231 treatment. This poses a significant health and economic burden and the need to impose strict 232 standards to reduce the rate of cross-contamination in the laboratory cannot be overstated. It is 233 repeatedly demonstrated that coherent planning; experienced technicians and preparation of 234 the appropriate facilities will be effective in contamination prevention ${ }^{3}$. For this reason, the 235 WHO has produced comprehensive technical standards for mycobacteriology laboratories 236 (http://www.who.int/tb/laboratory/mycobacteriology-laboratory-manual.pdf).

237 Simple measures to limit laboratory cross-contamination include the use of separate areas for 238 the handling of positive and negative TB smears. In addition, first time sampling of swabs from 239 patients also should be conducted in separate room/part of the laboratory reserved for these 240 activities $^{40}$. Education of laboratory staff, strict conduction of epidemiological measures, 241 external controls and follow-up of proposed guidelines could reduce rate of TB cross242 contamination $^{11}$.

243 Additional measures are required for the identification of false-positive results and avoidance 244 of the administration of unnecessary treatments to subjects with false-positive cultures. Our 245 study demonstrated a remarkable $15 \%$ incidence of false-positive results among single positive 246 TB cultures, suggesting it is a prime target for interventions aimed to reduce the unneeded 247 administration of anti-tubercular medications. The American Thoracic Society, Infectious 
248 Disease Society of America and Centers for Disease Control and Prevention recently issued 249 Guidelines for the diagnosis of tuberculosis, suggesting the need of confirmatory tests 250 following an initial positive mycobacterial culture, acknowledging that false-positive results 251 are common ${ }^{43}$. Based on our findings, it appears appropriate to delay the initiation of anti252 tubercular treatment until the acquisition of a second, confirmatory TB culture, especially in 253 atypical presentations if the clinical condition of the patient allows such a delay. Moreover, 254 when the obtained smear is negative and culture results are inconsistent with clinical 255 symptoms, laboratory staff should perform genotyping methods aimed to distinguish if the 256 result is a true or false-positive. Since this method is not precise for strains with less than 6 257 copies of IS6110, other methods including mycobacterial interspersed repetitive units (MIRU) 258 and spoligotyping could be helpful ${ }^{41-42}$. Contaminated specimens could be detected by 259 genotyping, as well as identification of the source of contamination and detection of re260 infection with same strain ${ }^{15}$. Although NGS remains cost prohibitive for resource-challenged 261 countries, this approach overcomes many of the significant challenges associated with 262 limitations of other less comprehensive molecular tests by providing rapid, detailed sequence 263 information for multiple gene regions or whole genomes of interest. However, the uptake of 264 these technologies for DR-TB diagnosis has been hindered by concerns regarding costs, 265 integration into existing laboratory workflows, technical training and skill requirements for 266 utilization of the technology and clinical interpretation of sequencing data ${ }^{14,44}$. The genetic 267 analysis using NGS has enabled rapid genome analysis with minimal sample preparation time 268 (1 to 2 days) at relatively moderate costs when multiple samples are analyzed per run. Reagent 269 expenses can be marginally decreased by combining 24 to 48 samples per sequencing run. 270 Additionally, a qPCR specific for M. tuberculosis and used prior to NGS can be employed for 271 the prediction of genomic sequencing success, a helpful strategy for reducing $\operatorname{costs}^{44}$. 
272 Obtaining false-positive results causes a delay in the correct diagnosis being reached, which 273 further delays starting the appropriate treatment, or not receiving the necessary management. 274 It also leads to increased costs due to hospitalization length, nursing expenses and non-medical $275 \operatorname{costs}^{3}$. By including the false-positive TB cases in the overall number of positive cases, the 276 prevalence of TB is falsely elevated. In addition, published results with false-positive TB cases 277 contribute to incorrect interpretation of epidemiological data. Consequently, there is no proper 278 estimation of TB risk in many countries.

279 An additional complication is drug resistant TB, especially if such strains are present in the 280 body of the "contaminator". In this case, the wrong patient with false-positive results, is treated 281 with second-line TB drugs, that additionally increase financial and health costs. From 1998 to 2821999 in the United States of America, every false diagnosis cost the health care system 10,873 283 dollars ${ }^{45}$. It is estimated that annually approximately 10 million dollars of excessive costs are 284 imposed to health system, not only for incorrect TB treatment, but also for physical harm after 285 use of anti-TB drugs and psychological pressures - this data could not be easily ignored ${ }^{2}$.

286 Although complete elimination of false-positive results obtained from the culture is the main 287 goal of every mycobacteriological laboratory, several factors still cause false-positivity of the 288 culture plate. In the current meta-review, several factors were highlighted as the most 289 significant for causing false-positivity of TB culture (Supplementary table). These include, 290 error in the performance of the laboratory technician, reagent contamination and the presence 291 of aerosols in the workplace. Aerosols containing live M. tuberculosis are created during the 292 removal of samples which can survive for a long period in harsh environmental conditions and 293 small areas. They have a major role in the contamination of reagents and instruments such as 294 pipettes or lids of containers ${ }^{5,46}$. In addition, inadequately sterilized bronchoscope may lead to 295 false positive results as well as transmission of the infection ${ }^{33}$. 
296 One of the included studies found unexpectedly high levels of cross-contamination $(18.2 \%)^{6}$. 297 The authors reported several large clusters of false-positive samples as a result of cross298 contamination. Characteristically, they identified two clusters of 9 and 5 false-positive samples 299 (9\% of all included samples) that were contaminated in the laboratory by a single true positive 300 culture each. This study was an outlier and the laboratory performance was below standards. 301 For this reason, we excluded this study in a sensitivity analysis. Our findings were not changed 302 by the omission of this study.

303 Our study has several strengths. Firstly, we conducted an extensive systematic review of five 304 online databases and our findings are based on a large number of studies, evaluating almost 30530,000 TB cultures. However, we did not identify any studies using NGS, which may offer a 306 more accurate assessment to identify possible laboratory cross-contamination. This is unlikely 307 to affect our estimates, as the identified studies implemented rigorous methods for identifying 308 laboratory cross-contamination. The quality of the available evidence was good and all 309 included studies adequately reported on the methodology used to identify laboratory cross310 contamination. Our results are at risk of publication bias and this may have led to a slight 311 overestimation of the prevalence of laboratory cross-contamination. Many were specifically 312 conducted to evaluate the incidence of cross-contamination and employed exhaustive methods 313 to identify false-positive results and cross-contamination. On the other hand, the variability in 314 methods used among different studies led to a significant (but expected) heterogeneity in our 315 results. When heterogeneity $\left(\mathrm{I}^{2}\right)$ is higher than $75 \%$, the quality of the pooled estimate is very 316 limited. However, in our sensitivity analyses, we were able to resolve the observed 317 heterogeneity and that did not lead to significant alterations, supporting the robustness of our 318 results. In addition, our results are at risk of publication bias, as evident by our funnel plot 319 (figure 3). Finally, we did not prospectively register the protocol of this meta-analysis, but we 

33

used standard methodology suggested by the Cochrane Collaboration, to prospectively address a clearly defined research question.

\section{Conclusion}

To our knowledge, this is the first comprehensive systematic review and meta-analysis evaluating the incidence of $M$. tuberculosis laboratory cross-contamination. We found a remarkably high incidence, $2 \%$ of all positive TB cultures and $15 \%$ of all single-positive TB cultures represent false-positive results due to laboratory cross-contamination. This is associated with a significant therapeutic and economic burden. Therefore, there is an urgent need for the adoption of a strict technical standard aiming to prevent or identify laboratory cross-contamination and false positive TB results.

Ethics approval and consent to publish: Not applicable (Meta review article).

Consent for publication: Not applicable.

Availability of data and material: Please contact author for data requests.

Competing interests: The authors declare that they have no conflict of interest relevant to this work.

Authors' contributions: MP, HK, MTR, EA, AB, JR, BM, HSK, AGM, MA carried out the systematic review and meta-analyses analyses and drafted the manuscript. AGM provided methodological expertise. AS, KHA, MA, EA participated in the design of the study and coordination and helped to draft the manuscript. All authors read and approved the final manuscript.

\section{Acknowledgment}

343 This study was supported by the Iranian National Sciences Foundation (Grant No: 843599) and 344 Tabriz University of Medical Sciences (Grant No: 37876). AGM is supported by the National 
345 Institute for Health Research Manchester Biomedical Research Centre (NIHR Manchester 346 BRC). Dr Aleksandra Barac's scientific work and research is supported by the Project of 347 Ministry of Education, Science and Technology of the Republic of Serbia (No. III45005).

349 Figure and Table Legends:

350 Figure 1. PRISMA flow diagram of the systematic review process

351 Figure 2. Risk of Bias of the included studies using the National Institutes of Health (NIH) 352 Quality Assessment Tool for Observational Cohort and Cross-Sectional Studies. Domains: (1) 353 Was the research question or objective in this paper clearly states? (2) Was the study population 354 clearly specified and defined? (3) Was the participation rate of eligible persons at least 50\%? 355 (4) Were all the subjects selected or recruited from the same or similar populations (including 356 the same time period)? Were inclusion and exclusion criteria for being in the study prespecified 357 and applied uniformly to all participants? (5) Was a sample size justification, power description 358 or variance and effect estimates provided? (6) For the analyses in this paper, were the 359 exposure(s) of interest measured prior to the outcome(s) being measured? (7) Was the 360 timeframe sufficient so that one could reasonably expect to see an association between 361 exposure and outcome if it existed? (8) For exposures that can vary in amount or level, did the 362 study examine different levels of the exposure as related to the outcome (e.g., categories of 363 exposure, or exposure measured as continuous variable)? (9) Were the exposure measures 364 (independent variables) clearly defined, valid, reliable, and implemented consistently across 365 all study participants? (10) Was the exposure(s) assessed more than once over time? (11) Were 366 the outcome measures (dependent variables) clearly defined, valid, reliable, and implemented 367 consistently across all study participants? (12) Were the outcome assessors blinded to the 368 exposure status of participants? (13) Was loss to follow-up after baseline $20 \%$ or less? (14) 
Were key potential confounding variables measured and adjusted statistically for their impact

on the relationship between exposure(s) and outcome(s)?

371 Figure 3. Funnel plots evaluating the publication bias of the included studies

372 Figure 4. Forest plot diagram of the meta-analyses: (a) Incidence of laboratory cross373 contamination among all positive cultures, (b) Incidence of laboratory cross-contamination 374 among single positive culture samples, (c) Incidence of laboratory cross-contamination among 375 single positive culture samples, after excluding two studies with unexpectedly high proportions. (d) Incidence of false-positive results among all positive results.

Table 1. Characteristics of the included studies

379 Table 2. Causes of $M$. tuberculosis cross-contamination that were identified in the included 380 studies

381

\section{References}

1. Rashedi J, Mahdavi Poor B, Rafi A, Asgharzadeh M, Abdolalizadeh J, Moaddab SR. Multidrug-resistant tuberculosis in north-west of Iran and Republic of Azerbaijan: a major public health concern for Iranian people. Journal of research in health sciences. 2015;15(2):101-103.

2. Organization WHO. Global tuberculosis report 2018. 2018.

3. de Boer AS, Blommerde B, de Haas PE, et al. False-positive mycobacterium tuberculosis cultures in 44 laboratories in The Netherlands (1993 to 2000): incidence, risk factors, and consequences. J Clin Microbiol. 2002;40(11):4004-4009.

4. de CRM, Soini H, Roscanni GC, Jaques M, Villares MC, Musser JM. Extensive crosscontamination of specimens with Mycobacterium tuberculosis in a reference laboratory. J Clin Microbiol. 1999;37(4):916-919.

5. Burman WJ, Reves RR. Review of false-positive cultures for Mycobacterium tuberculosis and recommendations for avoiding unnecessary treatment. Clinical infectious diseases : an official publication of the Infectious Diseases Society of America. 2000;31(6):1390-1395.

6. Martinez M, Garcia de Viedma D, Alonso M, et al. Impact of laboratory cross-contamination on molecular epidemiology studies of tuberculosis. J Clin Microbiol. 2006;44(8):2967-2969.

7. Small PM, McClenny NB, Singh SP, Schoolnik GK, Tompkins LS, Mickelsen PA. Molecular strain typing of Mycobacterium tuberculosis to confirm cross-contamination in the mycobacteriology laboratory and modification of procedures to minimize occurrence of false-positive cultures. J Clin Microbiol. 1993;31(7):1677-1682.

8. Asgharzadeh M, Shahbabian K, Majidi J, et al. IS6110 restriction fragment length polymorphism typing of Mycobacterium tuberculosis isolates from East Azerbaijan Province of Iran. Memorias do Instituto Oswaldo Cruz. 2006;101(5):517-521.

9. van Embden JD, Cave MD, Crawford JT, et al. Strain identification of Mycobacterium tuberculosis by DNA fingerprinting: recommendations for a standardized methodology. J Clin Microbiol. 1993;31(2):406-409.

10. Asgharzadeh M, Khakpour M, Salehi TZ, Kafil HS. Use of mycobacterial interspersed repetitive unit-variable-number tandem repeat typing to study Mycobacterium tuberculosis isolates 
from East Azarbaijan province of Iran. Pakistan journal of biological sciences : PJBS. 2007;10(21):3769-3777.

11. Lee MR, Chung KP, Chen WT, et al. Epidemiologic surveillance to detect false-positive Mycobacterium tuberculosis cultures. Diagnostic microbiology and infectious disease. 2012;73(4):343349.

12. Burman WJ, Stone BL, Reves RR, et al. The incidence of false-positive cultures for Mycobacterium tuberculosis. American journal of respiratory and critical care medicine. 1997;155(1):321-326.

13. Gutierrez M, Vincent V, Aubert D, et al. Molecular fingerprinting of Mycobacterium tuberculosisand risk factors for tuberculosis transmission in Paris, France, and surrounding area. Journal of clinical microbiology. 1998;36(2):486-492.

14. Breese PE, Burman WJ, Hildred M, et al. The effect of changes in laboratory practices on the rate of false-positive cultures for Mycobacterium tuberculosis. Archives of pathology \& laboratory medicine. 2001;125(9):1213-1216.

15. Bauer J, Thomsen VO, Poulsen S, et al. False-positive results from cultures of Mycobacterium tuberculosis due to laboratory cross-contamination confirmed by restriction fragment length polymporphism. J Clin Microbiol. 1997;35(4):998-991

16. Behr MA, Warren SA, Salamon H, et al. Transmission of Mycobacterium tuberculosis from patients smear-negative for acid-fast bacilli. Lancet. 1999;353:444.

17. Dahle UR, Sandven P, Heldal E, Caugant DA. Continued low rates of transmission of Mycobacterium tuberculosis in Norway. J Clin Microbiol. 2003;41(7):2968-2973.

18. Braden CR, Templeton GL, Stead WW, et al. Retrospective detection of laboratory crosscontamination of Mycobacterium tuberculosis cultures with use of DNA fingerprint analysis. Clinical Infectious Diseases. 1997;24:35-40.

19. Dahle UR, Sandven P, Heldal E, et al. Molecular epidemiology of Mycobacterium tuberculosis in Norway. J Clin Microbiol. 2001;29(5):1802-1807.

20. Fujikane T, Fujiuchi S, Yamazaki Y, et al. Molecular epidemiology of tuberculosis in the north Hokkaido district of Japan. The international journal of tuberculosis and lung disease : the official journal of the International Union against Tuberculosis and Lung Disease. 2004;8(1):39-44.

21. Hernandez-Garduno E, Cook V, Kunimoto D, Elwood RK, Black WA, FitzGerald JM. Transmission of tuberculosis from smear negative patients: a molecular epidemiology study. Thorax. 2004;59(4):286-290.

22. Asgharzadeh M, Kafil HS, Roudsary AA, Hanifi GR. Tuberculosis transmission in Northwest of Iran: using MIRU-VNTR, ETR-VNTR and IS6110-RFLP methods. Infection, genetics and evolution : journal of molecular epidemiology and evolutionary genetics in infectious diseases. 2011;11(1):124131.

23. Ribeiro FK, Lemos EM, Hadad DJ, et al. Evaluation of low-colony-number counts of Mycobacterium tuberculosis on solid media as a microbiological marker of cross-contamination. J Clin Microbiol. 2009;47(6):1950-1952.

24. Allix-Beguec C, Fauville-Dufaux M, Supply P. Three-year population-based evaluation of standardized mycobacterial interspersed repetitive-unit-variable-number tandem-repeat typing of Mycobacterium tuberculosis. J Clin Microbiol. 2008;46(4):1398-1406.

25. Yan JJ, Jou R, Ko WC, Wu JJ, Yang ML, Chen HM. The use of variable-number tandem-repeat mycobacterial interspersed repetitive unit typing to identify laboratory cross-contamination with Mycobacterium tuberculosis. Diagnostic microbiology and infectious disease. 2005;52(1):21-28.

26. Drobniewski FA, Gibson A, Ruddy M, et al. Evaluation and utilization as a public health tool of a national molecular epidemiological Tuberculosis outbreak database within the United Kingdom from 1997 to 2001. J Clin Microbiol. 2003;41(5):1861-1868.

27. Gascoyne-Binzi DM, Barlow REL, Frothingham R, et al. Rapid identification of laboratory contamination with Mycobacterium tuberculosis using variable number tandem repeat analysis. J Clin Microbiol. 2001;39(1):69-74.

28. Globan M, Lavender C, Leslie D, et al. Molecular epidemiology of tuberculosis in Victoria, Australia, reveals low level of transmission. Int J Tuberc Lung Dis. 2016;20(5):652-658. 
29. Glynn Jr, Yates MD, Crampin AC, et al. DNA fingerprint changes in Tuberculosis: Reinfection, evolution or laboratory error? J Infect Dis. 2004;190:1158-1166.

30. Godfrey-FAussett P, Sonnenberg P, Shearer SC, et al. Tuberculosis control and molecular epidemiology in a South African gold-mining community. Lancet. 2000;356:1066.

31. Hayward AC, Goss S, Drobniewski F, et al. The molecular epidemiology of tuberculosis in inner London. Epidemiol Infect. 2002;128:175-184.

32. Jasmer RM, Roemer M, Hamilton $\mathrm{J}$, et al. A prospective multicenter study of laboratory cross0contamination of Mycobacterium tuberculosis cultures. Emerg Infect Dis. 2002;8(11):12601263.

33. Jasmer RM, Bozeman L, Schwartzman K, et al. Recurrent Tuberculosis in United States and Canada: Relapse or Reinfection? Am J Respir Crit Care Med. 2004;170(12):1360-1366.

34. Lai CC, Tan CK, Lin SH, et al. Molecular evidence of false-positive cultures of Mycobacterium tuberculosis in a Taiwanese hospital with a high incidence of TB. Chest. 2010;137(5):1065-1070.

35. McConkey SJ, Williams M, Weiss D, et al. Prospective use of molecular typing of Mycobacterium tuberculosis by use of restriction fragment-length polymporphism in a public tuberculosis-control program. Clinical Infectious Diseases. 2002;34:612-619.

36. Nitta AT, Knowles LA, Kim J, et al. Limited transmission of multidrug-resistant Tuberculosis despite a high proportion of infectious cases in Los Angeles County, California. Am J Respir Crit Care Med. 2002;165:812-817.

37. Maguire H, Dale JW, McHugh TD, et al. Molecular epidemiology of tuberculosis in London 19957 showing low rate of active transmission. Thorax. 2002;57:617-622

38. Ruddy M, McHugh TD, Dale JW, et al. Estimation of the rate of unrecognized cross-contamination with Mycobacterium tuberculosis in London Microbiology Laboratories. J Clin Microbiol. 2002;40(11):4100-4104.

39. Thumamo BP, Asuquo AE, Abia-Bassey LN, et al. Molecular epidemiology and genetic diversity of Mycobacterium tuberculosis complex in the Cross River State, Nigeria. Infect Genet Evol. 2012;12(4):671-677.

40. Carroll NM, Richardson M, Engelke E, de Kock M, Lombard C, van Helden PD. Reduction of the rate of false-positive cultures of Mycobacterium tuberculosis in a laboratory with a high culture positivity rate. Clinical chemistry and laboratory medicine. 2002;40(9):888-892.

41. Jonsson J, Hoffner S, Berggren I, et al. Comparison between RFLP and MIRU-VNTR genotyping of Mycobacterium tuberculosis strains isolated in Stockholm 2009 to 2011. PloS one. 2014;9(4):e95159.

42. Kamerbeek J, Schouls L, Kolk A, et al. Simultaneous detection and strain differentiation of Mycobacterium tuberculosis for diagnosis and epidemiology. J Clin Microbiol. 1997;35(4):907-914.

43. Lewinsohn DM, Leonard MK, LoBue PA, et al. Official American Thoracic Society/Infectious Diseases Society of America/Centers for Disease Control and Prevention Clinical Practice Guidelines: Diagnosis of Tuberculosis in Adults and Children. Clin Infect Dis. 2017;64(2):111-115.

44. Daum LT, Konstantynovska OS, Solodiankin OS, et al. Next-Generation Sequencing for Characterizing Drug Resistance-Conferring Mycobacterium tuberculosis Genes from Clinical Isolates in the Ukraine.J Clin Microbiol. 2018;56(6).

45. Northrup JM, Miller AC, Nardell E, et al. Estimated costs of false laboratory diagnoses of tuberculosis in three patients. Emerging infectious diseases. 2002;8(11):1264-1270.

46. Larson JL, Lambert L, Stricof RL, Driscoll J, McGarry MA, Ridzon R. Potential nosocomial exposure to Mycobacterium tuberculosis from a bronchoscope. Infection control and hospital epidemiology. 2003;24(11):825-830. 


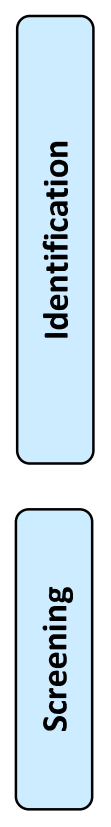

\section{Records identified through}

database searching $(n=1,033)$
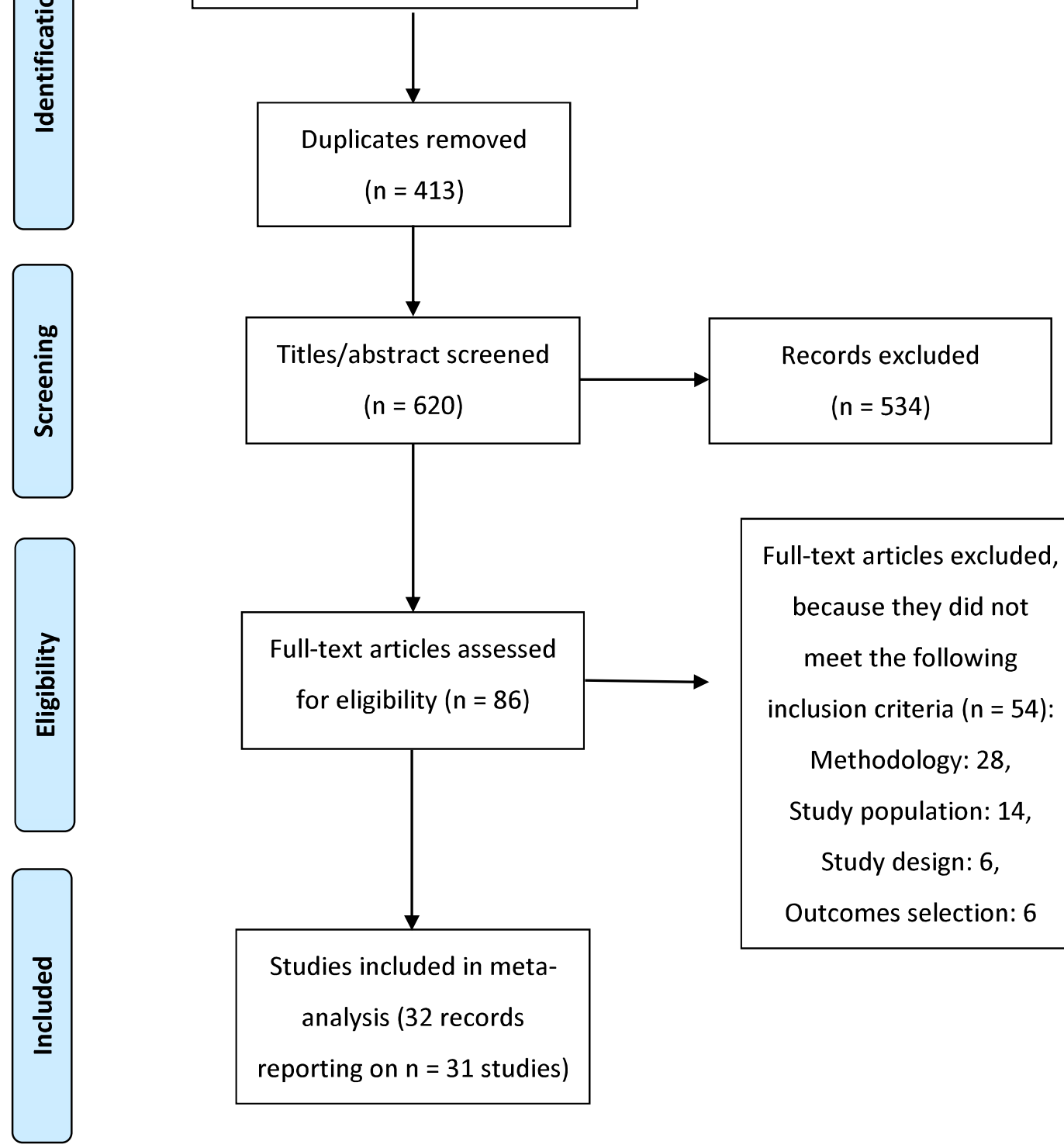

Full-text articles excluded, because they did not meet the following inclusion criteria $(n=54)$ : Methodology: 28, Study population: 14 , Study design: 6, Outcomes selection: 6 


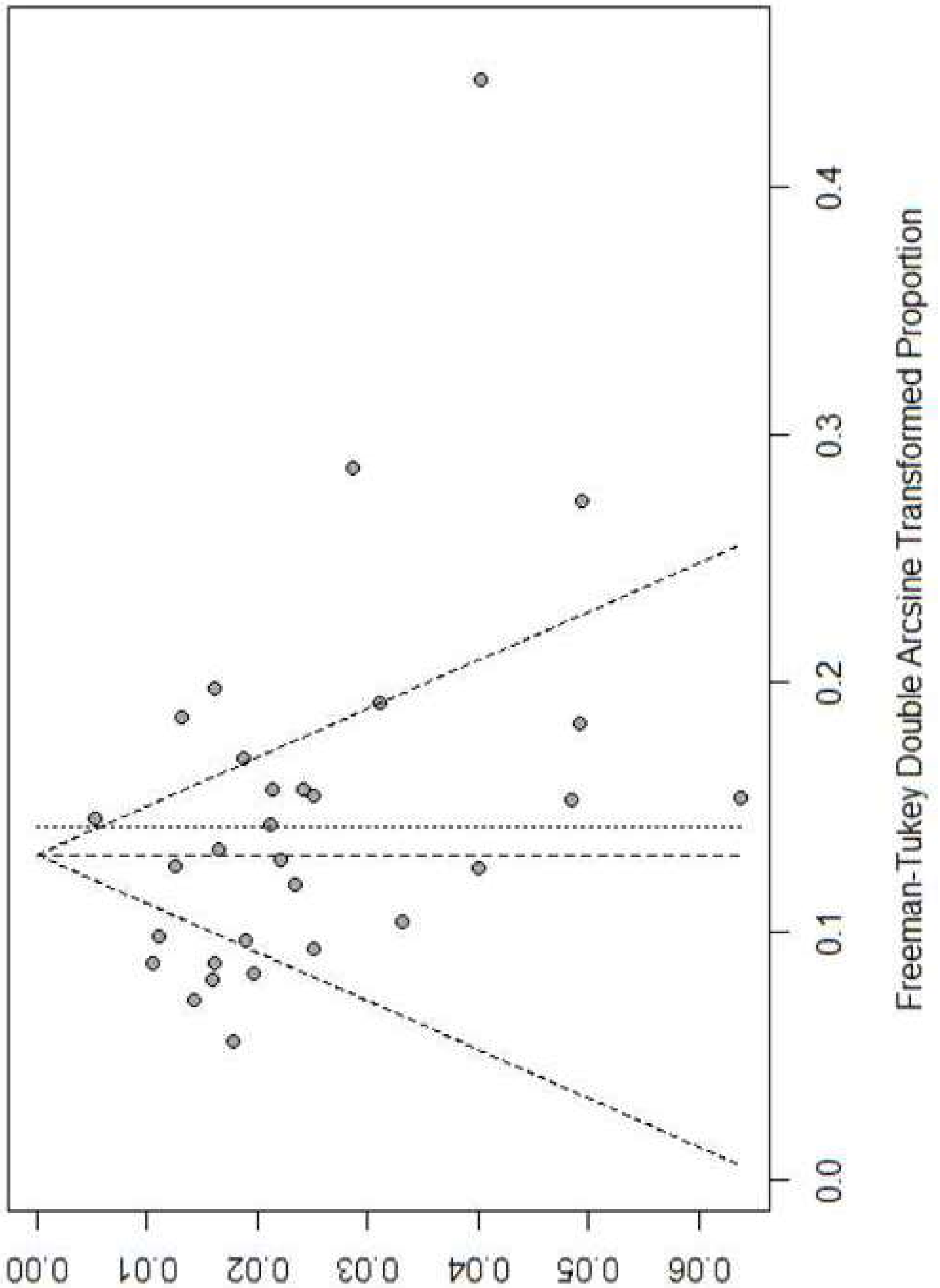

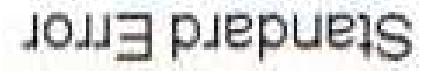


F"

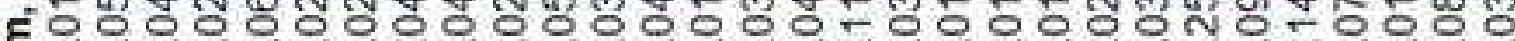

0000000000000000000000000000000

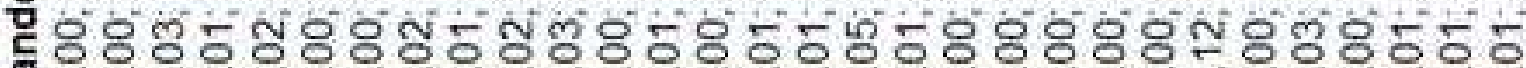

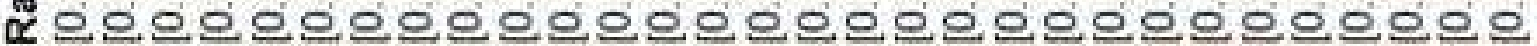

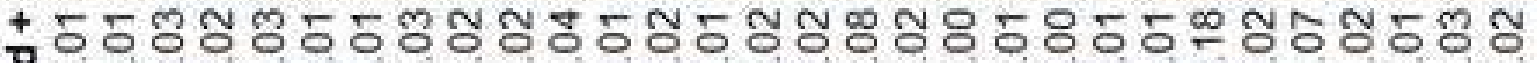

¿000000000000000000000000000000

$x$

$\geq$

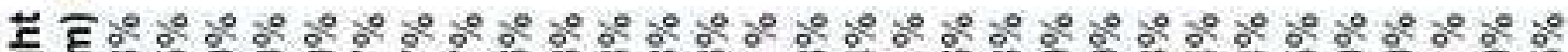

T.

\.

3

t

5

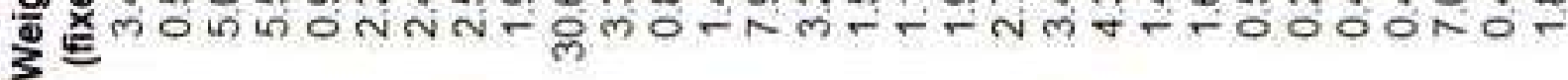

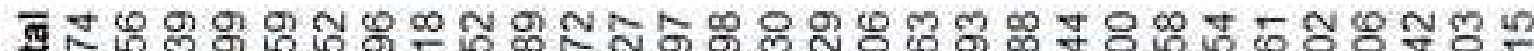
은견

론 แั

ó

1

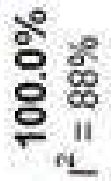

ণั่

m

v

is

o

5

농 


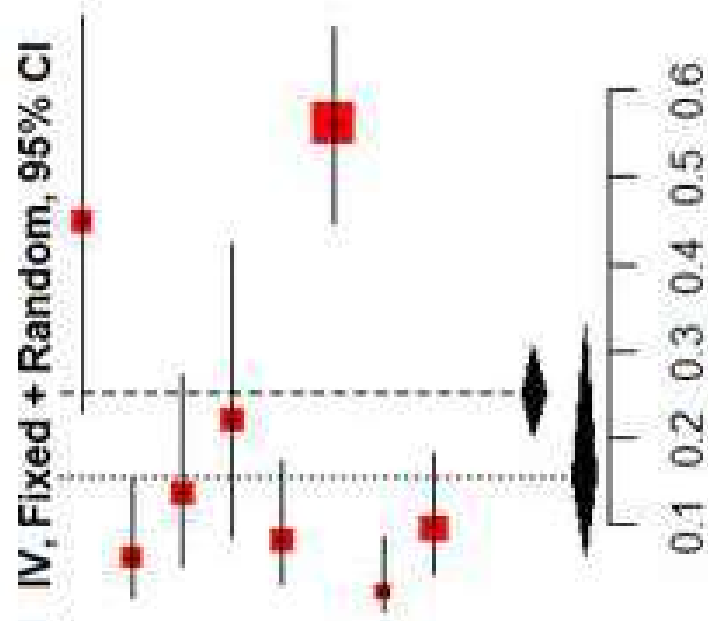

$\bar{v}$

ஃ̊

\%

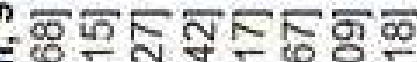
EO 0000000

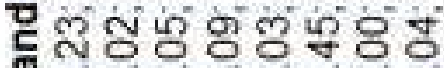
으응ㅇㅇㅇㅇㅇㅇㅛ +48 요요 I00000000 뜬 $\geq$

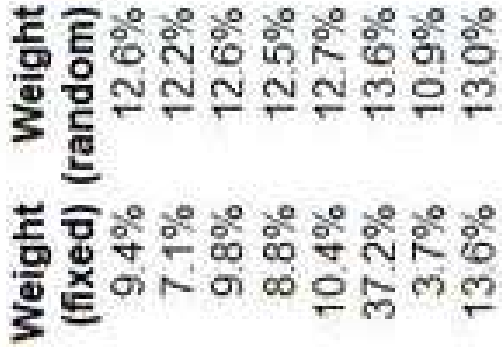

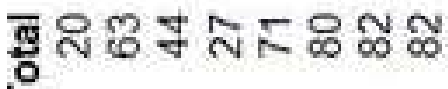
응 g 0 \& $0.0 \%$ in $N \infty$ ल ल 00 ல் 용 L8 40

त्र 


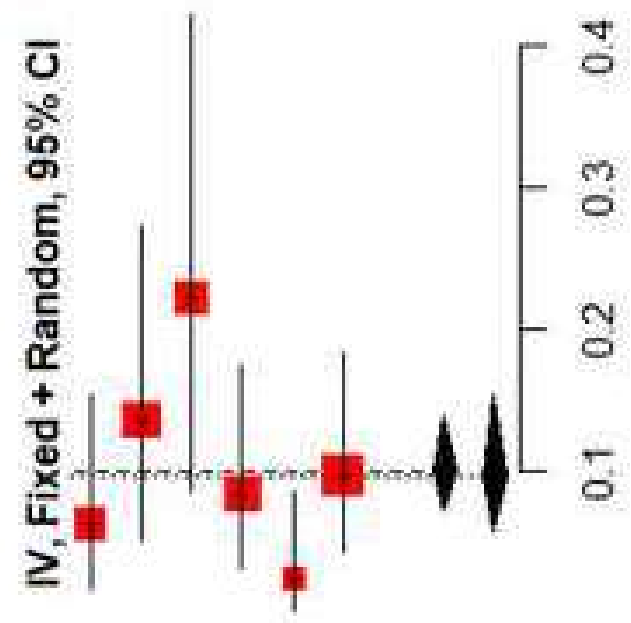

ธ

ㅇำ

\%下 חरक

EN 잉ㅇㅇㅇㅇㅇ

으응ㅇㅇㅇㅇㅇㅡ.

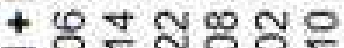

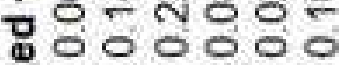

it

$\geq$

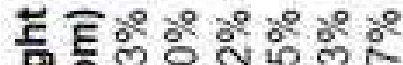
음 $\infty=\infty 0$ 용

\ $\frac{\mathrm{C}}{\mathrm{C}}+\leftarrow+\mathrm{N}$

는

도 꿍ㅇㅇㅇㅇㅇㅇㅇㅇ 웅

잉

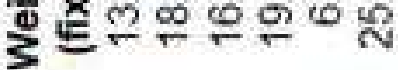

車

은

$\sum_{\frac{\mathrm{T}}{\mathrm{C}}}^{\mathrm{g}}$

๙

든ㄷำ

卷

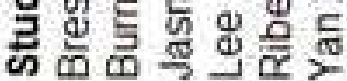

守吕

०.

ते

인은

으으

o 0

18

웅 혼

웅

g :

娄

ผั

?
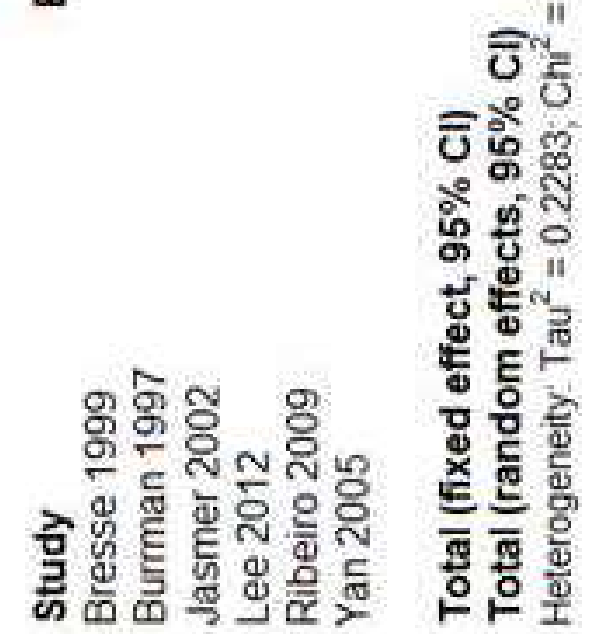


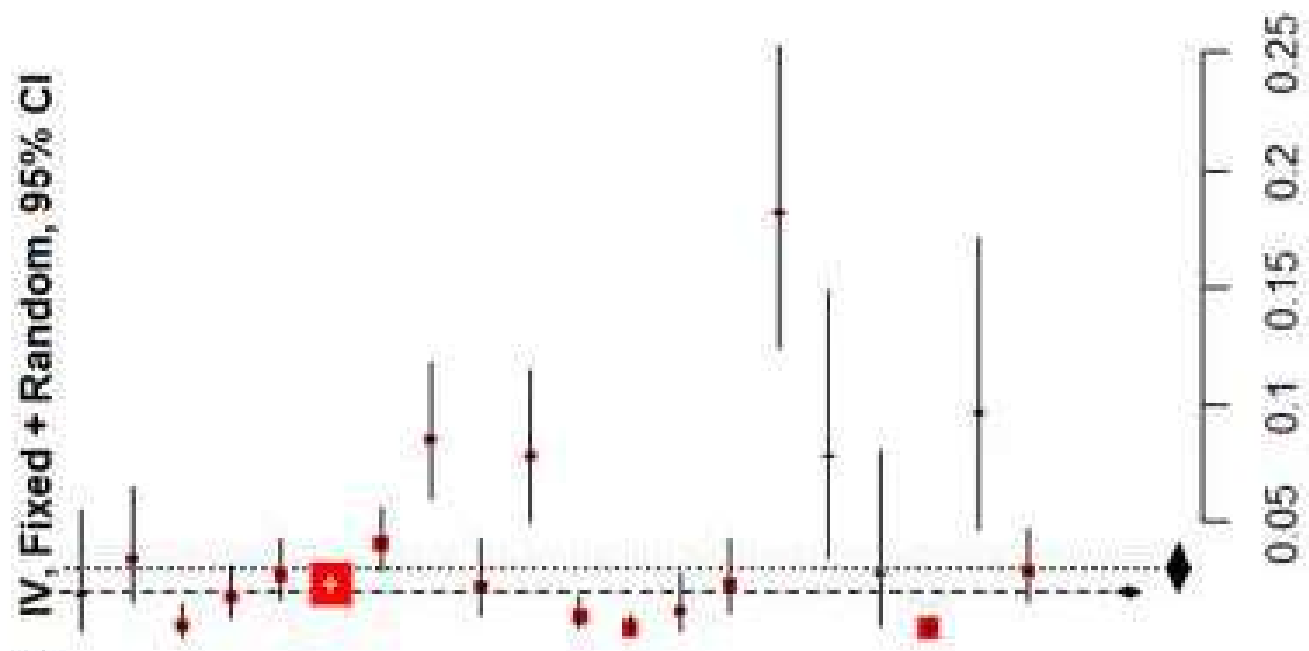

$\overline{0}$

ڤั

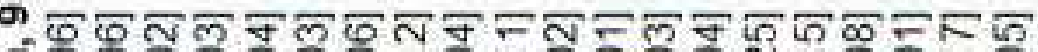

E0000000000 000000000000

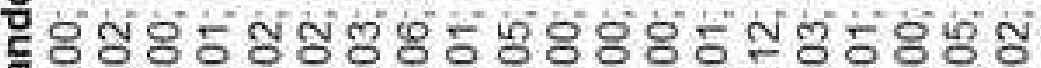

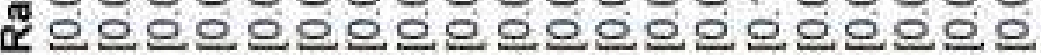

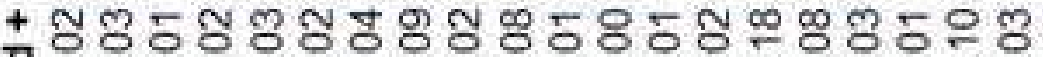

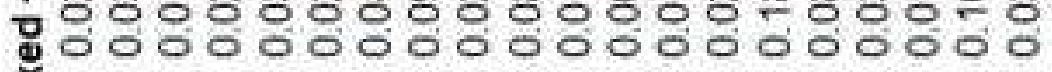

$x$

i⿳亠口冋.

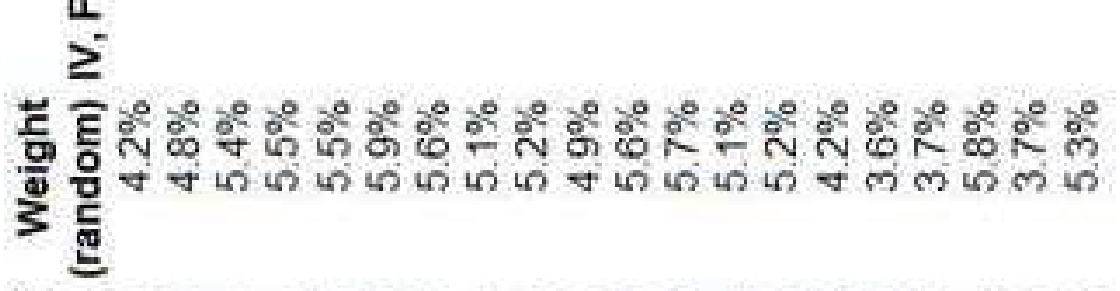

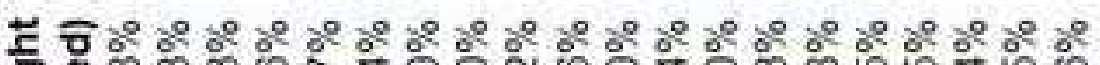

T.

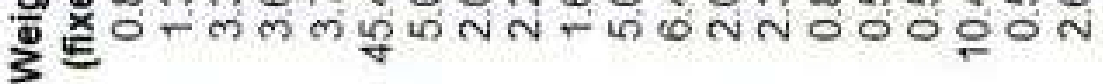

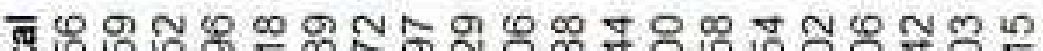
은 窎

쫑 잉 ชิํํㅇ 으으 옹 ठㅇํ

$1 \%$

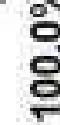

용

으 II

$\begin{array}{lll}8 & 1 & 5 \\ \circ & 0 \\ \circ & 0\end{array}$

$\div 0$

品

फ 


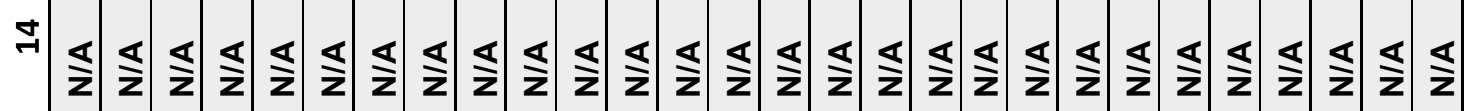

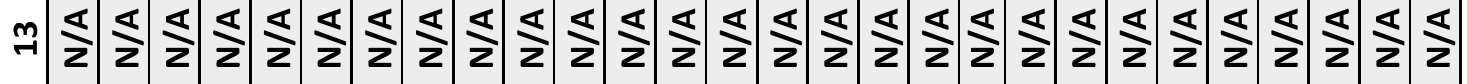

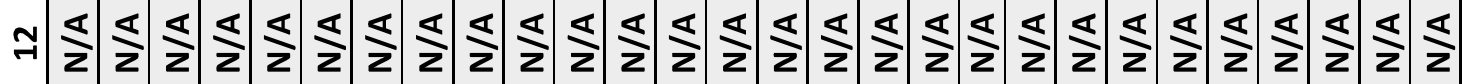

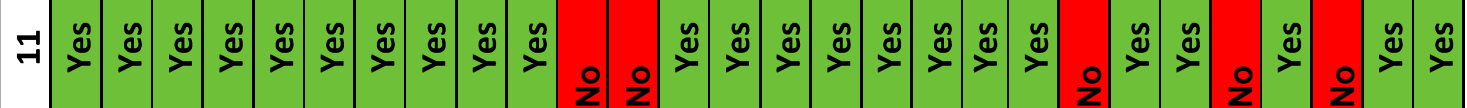

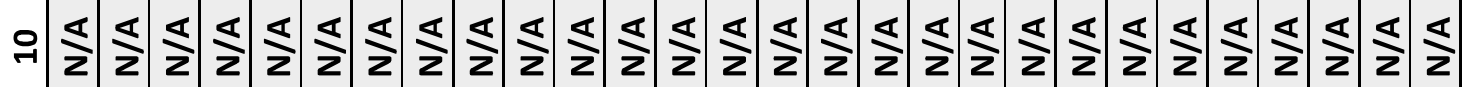

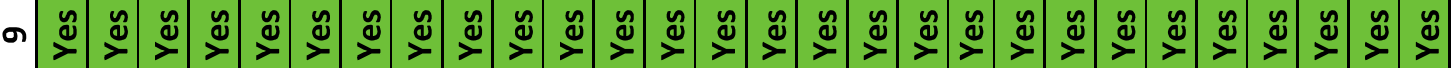

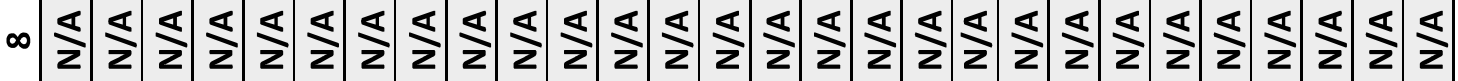

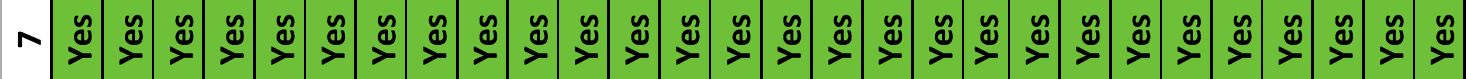

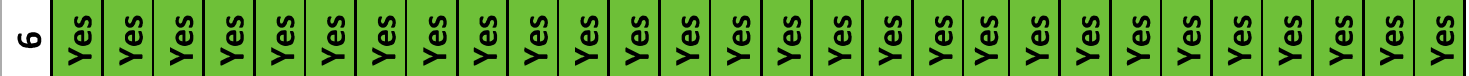

เn

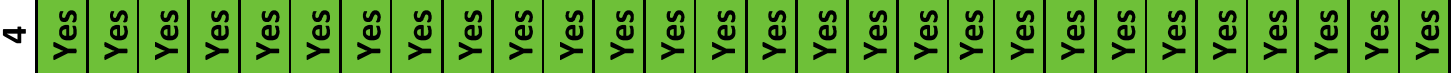

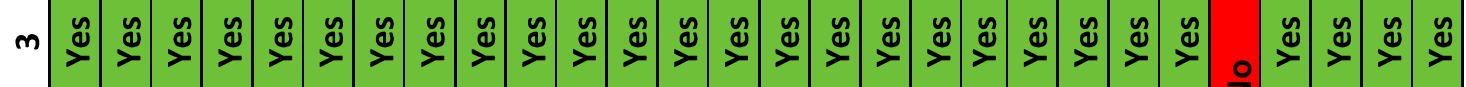

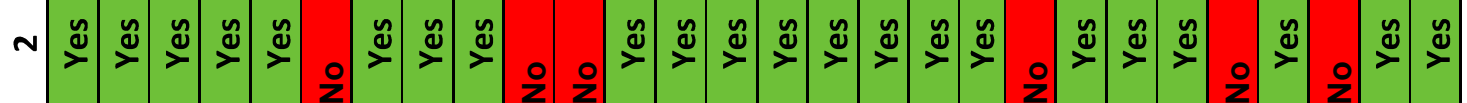

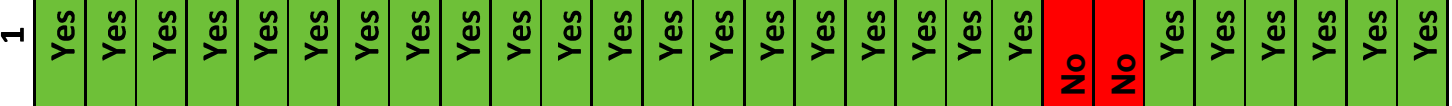

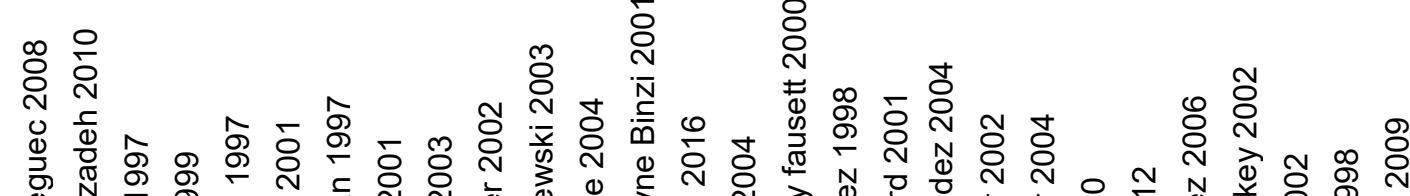

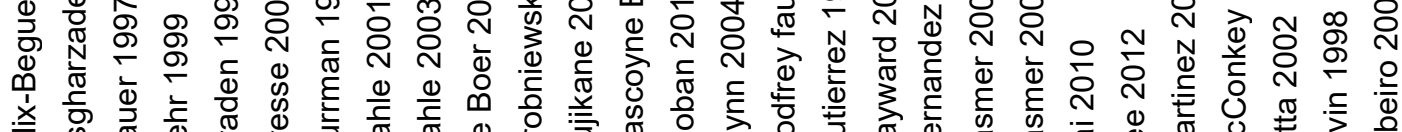

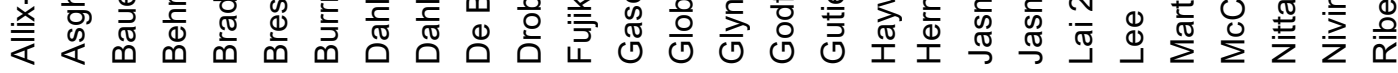




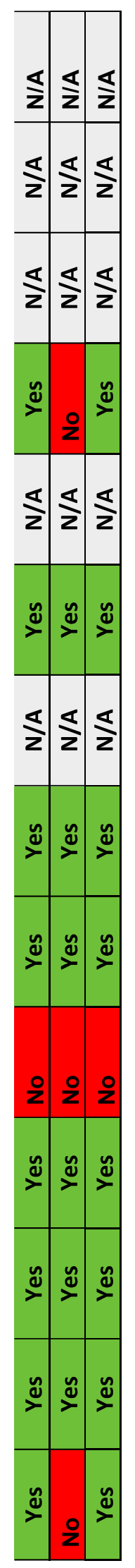

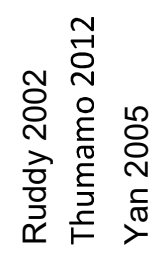




\begin{tabular}{|c|c|c|c|c|c|c|c|c|c|c|c|c|}
\hline 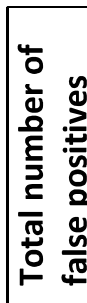 & & in & P & $-\gamma$ & in & $-r$ & & $\stackrel{\infty}{N}$ & ๓ & & & \\
\hline 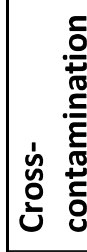 & $\approx$ & 0 & $m$ & N & $m$ & $\sim$ & 1 & $\stackrel{\infty}{N}$ & $\infty$ & $\sim$ & N & $\stackrel{0}{-1}$ \\
\hline 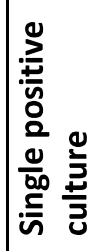 & & I & & & & $\infty$ & & & $\approx$ & & & \\
\hline 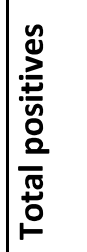 & 文 & 离 & $\overbrace{0}^{\infty}$ & 年 & \&্ণ & 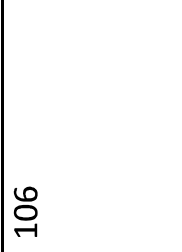 & 苟 & 苛 & $\stackrel{\sim}{\stackrel{n}{n}}$ & 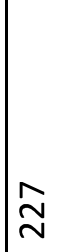 & হ̆ & হু \\
\hline 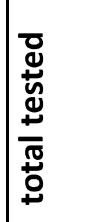 & & 恿 & & & & $\underset{\sim}{\stackrel{\mathscr{\sim}}{\sim}}$ & & & & & & \\
\hline 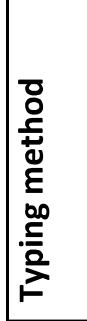 & 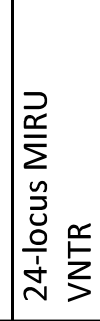 & 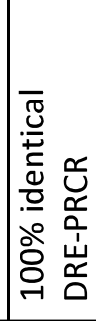 & 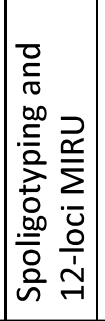 & 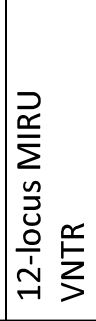 & 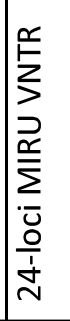 & 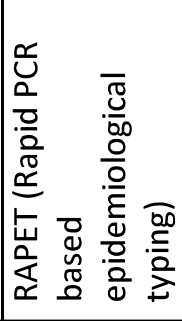 & 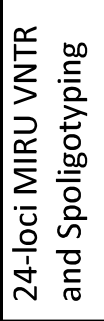 & 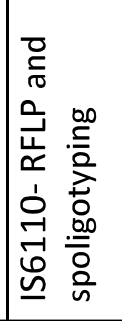 & 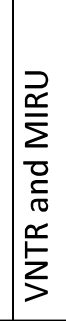 & 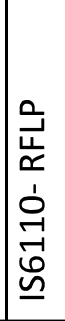 & 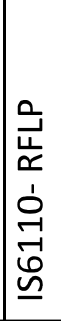 & 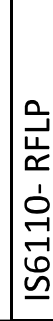 \\
\hline 六 & 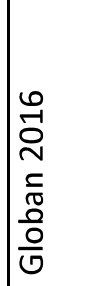 & 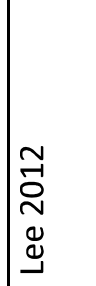 & 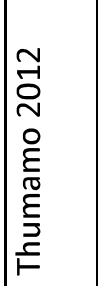 & 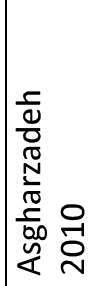 & 递 & 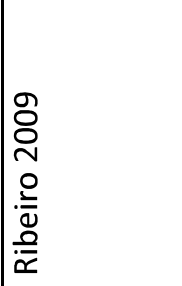 & 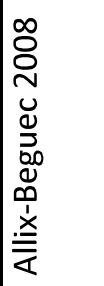 & 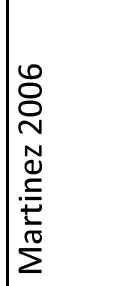 & 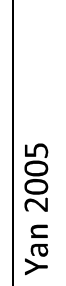 & 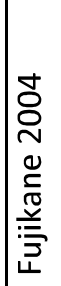 & 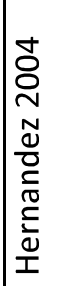 & 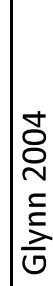 \\
\hline
\end{tabular}




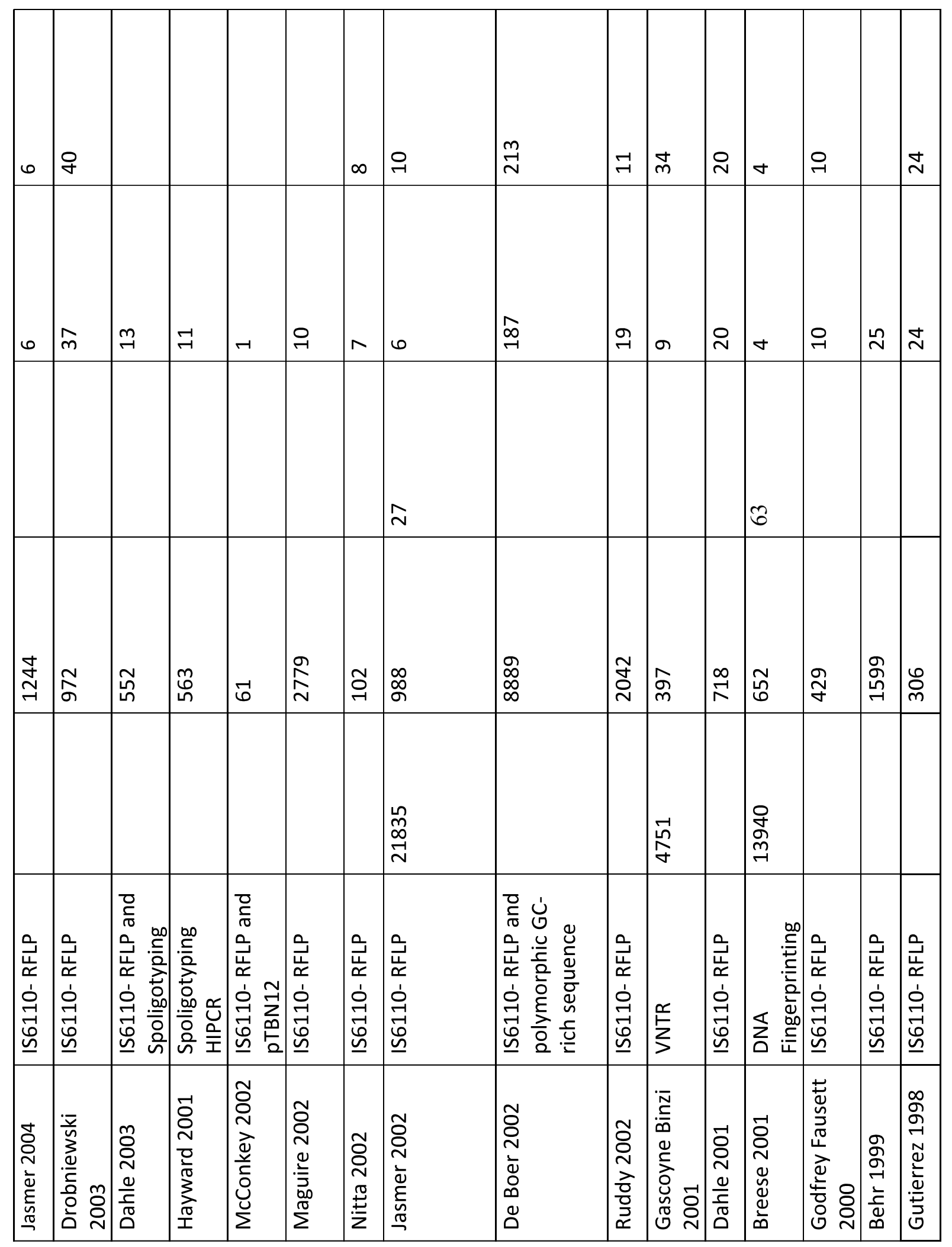




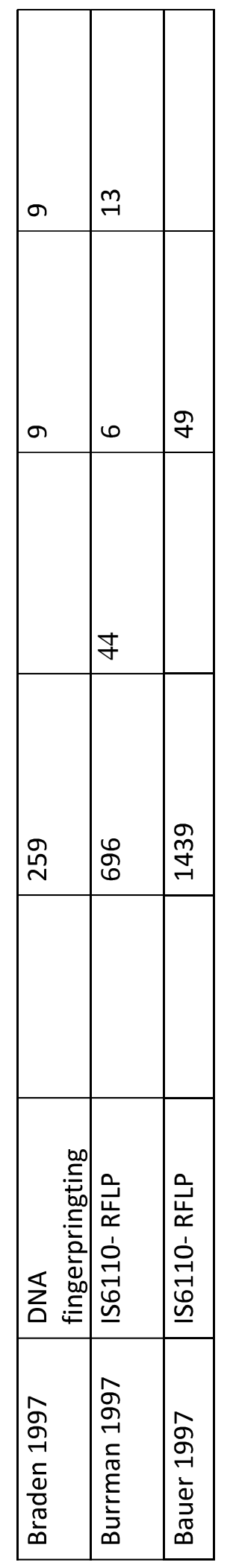




\begin{tabular}{|cccc|}
\hline No. & Factors & No. & Reference \\
\hline 1. & $\begin{array}{c}\text { Inappropriate technician's } \\
\text { laboratory work }\end{array}$ & 34 & 15 \\
\hline 2. & Contamination of reagents & 25 & $15,26,31,32,27$ \\
\hline 3. & Creation of aerosols & 24 & 3,26 \\
\hline 4. & Mislabeling & 16 & $3,5,28,18,22,26,37,32$ \\
\hline 5. & Contaminated equipment & 11 & 3,27 \\
\hline 6. & Poor laboratory techniques & 10 & 3,26 \\
\hline 7. & Contaminated bronchoscope & 4 & 27 \\
\hline 8. & Splashing & 2 & 32 \\
\hline 9. & Reprocessing of contaminated & 2 & 12 \\
\hline 10. & BACTEC needle carryover & 2 & 26 \\
\hline
\end{tabular}

2 